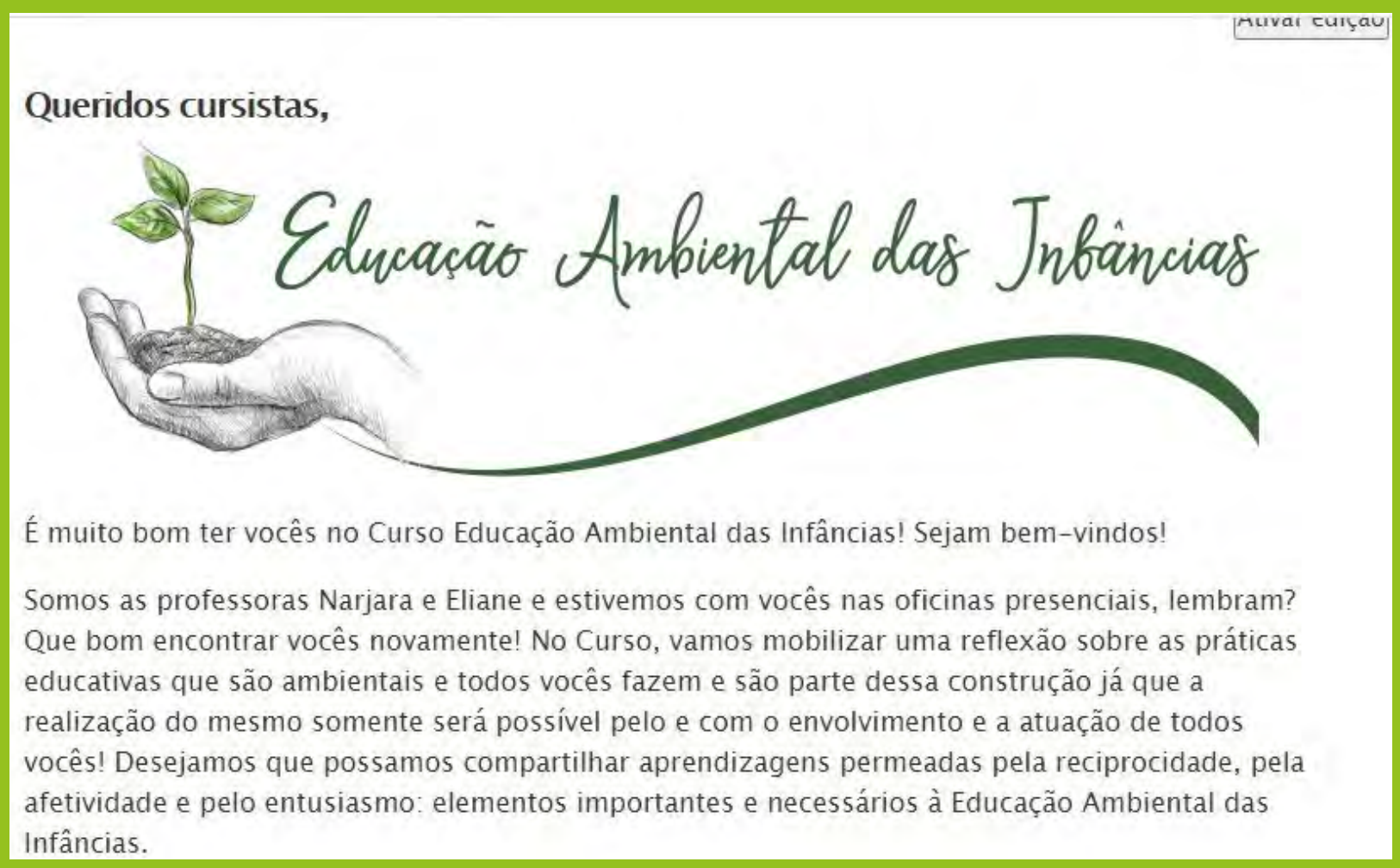

\title{
Estratégia na Educação Ambiental das Infâncias para potencializar o olhar bioecológico dos educadores
}

Eliane Lima Piske - e.nanny@hotmail.com¹

Narjara Mendes Garcia - narjaramg@gmail.com²

Maria Angela Mattar Yunes - mamyunes@gmail.com³

\section{RESUMO}

A conversa(ação) e construção da estratégia de Educação Ambiental das Infâncias objetivou estabelecer interlocução de concepções bioecológicas de desenvolvimento humano nas/das (com/para as) infâncias e os papéis dos educadores na educação das crianças. 0 entrelace experiencial proposto na investigação envolveu o protagonismo dos educadores das Redes Municipal, Estadual e em formação inicial na construção do Curso de Extensão intitulado Educação Ambiental das Infâncias, Projeto de Extensão da Universidade Federal do Rio Grande- FURG, no ano de 2018. Para a análise dos dados resultantes da conversa(ação) com 46 educadores das infâncias, utilizamos o software Sobek. As percepções bioecológicas de desenvolvimento humano foram evidenciadas pela pluralidade sistêmica de conversa(ação) e articulação contextualizada de experiências potencializadoras do olhar bioecológico dos educadores das infâncias com as crianças.

PALAVRAS-CHAVE: educação ambiental das infâncias; crianças; educadores; olhar bioecológico.

1 Doutoranda pelo Programa de Pós-Graduação em Educação Ambiental pela Universidade Federal do Rio Grande- PPGEA/ FURG. Bolsista CAPES. Professora de Educação Infantil da Rede Municipal de Pelotas/RS.

2 Doutora em Educação Ambiental pelo Programa de Pós-Graduação em Educação Ambiental- PPGEA/FURG. Professora do Instituto de Educação da Universidade Federal do Rio Grande- IE/FURG.

3 Doutora em Educação pela Pontifícia Universidade Católica de São Paulo- SP. Professora do Programa de Pós-Graduação em Psicologia, UNIVERSO, Niterói/Rio de Janeiro- RJ. 


\title{
Strategy for Environmental Education during Infancy to promote a bioecological approach of educators
}

\begin{abstract}
The conversation (action) to build the strategy for children's Environmental Education aimed to bring the dialogue between the bioecological conceptions of human development in (with / for) children and the roles of infancy educators. The experiential interface proposed in the investigation involved the protagonism of MunicipalandState educators in the construction of the Continuing Education Course entitled Environmental Education for Children, a project led by the Federal University of Rio Grande - FURG, in 2018. The analysis of data collected during the processes of conversation (action) with 46 kindergarten teachers was organized by the Sobek software. The bioecological perceptions of human development were highlighted by the systemic plurality of conversation (action) which helped to put into context the experiences that reinforce the bioecological approach of children's educators.
\end{abstract}

KEYWORDS: childhoods; environmental education; children; educators; bioecological look.

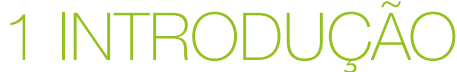

A pluralidade de infâncias instiga pesquisadoras a pensar nas interfaces entre a biologia-cultural (MATURANAEDÁVILA, 2009)eas dimensões dabioecologiado desenvolvimentohumano(BRONFENBRENNER, 2011). 0 presente artigo apresenta essas interconexões teóricas que estão em consonância com as microintervenções metodológicas sistêmicas no Curso de Extensão Educação Ambiental das Infâncias (CEEAI) pela Universidade Federal de Rio Grande- FURG.

0 Curso de Extensão foi pensado, planejado e organizado por pesquisadoras que compõem dois grandes coletivos: o Grupo Ecoinfâncias: Infâncias, Ambientes e Ludicidade e o Centro de Referência em Apoio as Famílias- CRAF/FURG. 0 grupo de Estudos e Pesquisa Ecoinfâncias foi criado em janeiro de 2018 , na Universidade Federal do Rio Grande - FURG, como parte das ações do Núcleo de Estudos e Pesquisa em Educação das Infâncias - NEPE e em parceria com o Centro de Referência em Apoio às Famílias- CRAF. 0 grupo tem como função compartilhar Pesquisas de Iniciação Científica, Mestrado e Doutorado com o foco na formação de educadores para o trabalho com as infâncias em ambientes lúdicos e educativos. As ações de investigação dos pesquisadores, estudantes e colaboradores estão associadas ao campo da Educação Ambiental, da Educação Infantil e da Educação Física com crianças. As pesquisas e as atividades de Extensão do grupo apresentam repercussões na produção de conhecimento e na formação dos professores da Educação Básica, dos estudantes dos cursos de Pedagogia e Educação Física, dos acadêmicos dos cursos de Pós-Graduação em Educação e em Educação Ambiental e dos educadores das infâncias em contextos formais e informais.

O CRAF foi criado no ano de 2012 e, atualmente, conta com seis Projetos de Extensão, sendo um deles conversa(ação) com os educadores das infâncias, o Programa é referência em famílias e em metodologias experienciais (PISKE et al., 2020; BERSCH et al., 2019). O Ecoinfâncias é composto por estudantes dos cursos de Pedagogia e Educação Física; bolsistas de Iniciação Científica; professoras da Rede Pública; mestrandos, doutorandos e pós-doutoranda do Programa de Pós-Graduação em Educação Ambiental; e pelas professoras pesquisadoras do Instituto de Educação da Universidade Federal do Rio Grande - FURG (PISKE; NEUWALD; GARCIA, 2018). As atuações, que vem sendo desenvolvidas pelos dois grupos, apresentam as demandas externas que fomentam a proposta do Curso de Extensão.

A ação extensionista conta com a parceria de bolsistas de Extensão, de Iniciação Científica, voluntárias e professoras colaboradoras na mediação das discussões com o público-alvo: educadores das infâncias, que correspondem tanto aos profissionais de educação (estudantes de licenciatura, monitores, educadores sociais, professores, recreacionistas etc.) como as figuras parentais e quaisquer outros cuidadores, sejam pais biológicos, adotivos, sociais e/ou avós (PISKE; YUNES; GARCIA, 2019).

A estratégia experiencial da pesquisa(ação) se realizou no ano de 2018 e envolveu o protagonismo dos educadores de múltiplos contextos ecológicos microssistêmicos, das cidades de Rio Grande, São Lourenço do Sul e Santo Antônio da Patrulha, todas situadas no Estado do Rio Grande do Sul-RS. 0 tripé: Ensino, Pesquisa e Extensão é o pressuposto metodológico proposto no curso, com o objetivo de estabelecer 
interlocução das concepções bioecológicas de desenvolvimento humano nas/das (com/para as) infâncias e os papéis dos educadores na educação das crianças.

A metodologia adotada visa a promover o olhar bioecológico na Educação Ambiental das Infâncias. 0 contexto se formou na conversa(ação) sistêmica com 46 educadores ambientais das infâncias, concluintes do CEEAI. 0 tecer sistemático capaz de mobilizar o olhar biolecológico advém de estudos que são realizados em contextos ecológicos microssistêmicos por meio da interação na Plataforma Moodle, onde os educadores das infâncias podem também estabelecer relações face a face.

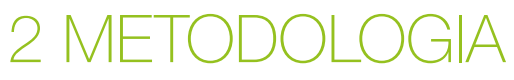

A conversa(ação) sistêmica com os educadores ambientais foi o ponto forte dessa investigação, que adotou como procedimento metodológico mecanismos de integração das concepções bioecológicas de desenvolvimento humano na organização do Curso de Extensão Educação Ambiental das Infâncias (CEEAI). 0 Curso foi planejado comencontros presenciais e a distância. As microintervenções psicocorporais foram realizadas e sensibilizadas em encontros presenciais. Os módulos do Curso aconteceram a distância, por meio da utilização da Plataforma Moodle.

Com as informações elencadas pelos educadores das infâncias nos encontros presenciais, foram organizados os módulos do CEEAl. Essa é uma estratégia para estabelecer interlocução entre o desenvolvimento humano na educação das crianças e investigar as práticas dos educadores das infâncias numa perspectiva sistêmica da Educação Ambiental. 0 estudo é de cunho qualitativo (MINAYO, 2010). Os encontros presenciais, construídos com os educadores das infâncias, contribuíram para alicerçar as atividades a distância, em que os educadores tiveram a oportunidade de criar planos de ação para serem desenvolvidos em seus locais de atuação, momento em que as crianças participam das atividades.

0 Curso aconteceu durante o ano de 2018 pela possibilidade da interação e da conversa(ação) com diferentes educadores ambientais das infâncias de múltiplos contextos ecológicos microssistêmicos. A seguir, serão apresentados os métodos e os participantes, além dos procedimentos éticos para a construção e realização do curso.

Instrumentos e participantes: foram oferecidas 30 vagas para cada Polo- Rio Grande, São Lourenço do Sul e Santo Antônio da Patrulha, todos no Estado do Rio Grande do Sul- RS. As turmas foram bastante heterogêneas com educadores das Redes Municipal, Estadual e Particular, além de estudantes de Graduação, salientamos que participaram educadores de diversas áreas do conhecimento, como: Pedagogia, Geografia, Educação Física, História e Letras. 0 Curso teve um encontro presencial e as demais atividades aconteceram via Plataforma Moodle. No Curso, foram ofertadas 90 vagas e preenchidas 80 . Destes, concluíram o Curso 46 educadores das infâncias. 0 Curso teve uma carga horária de 120 horas e a certificação foi feita via sistema; os educadores receberam por e-mail as chaves de autenticidade.

Procedimentos: o Curso foi organizado com cinco módulos experienciais que possibilitaram estabelecer uma conversa nos fóruns com os educadores. Vale mencionar, o embasamento teórico do Curso foi construído tendo em vista as temáticas de pesquisa de mestrandas e doutorandas do Programa de Pós-Graduação em Educação Ambiental, cada texto temático foi produzido em dupla e/ou trio pelas pesquisadoras. As proponentes do módulo 1 e do módulo 5 pensaram em atividades a partir das temáticas propostas nos módulos. A tabela a seguir foi organizada para apresentar as temáticas dos textos construídos e as atividades propostas: 


\section{Tabela 1 - Organização dos textos}

\section{MÓDULOS}

\section{ATIVIDADES PROPOSTAS}

Módulo 1- Educação Ambiental das Infâncias: ludicidade, culturas e ambiente (13 a 20 de agosto de 2018).
Fórum: como abordar as infâncias contemporâneas pelo propósito de valorizar as múltiplas linguagens entre e com as crianças e o ambiente?

Plano de Ação (apêndice C).
Módulo 2-Educação Ambiental Inclusiva das Infâncias (20 a 27 de agosto de 2018)
Fórum: vamos debater sobre a In/Exclusão como parte da crise ambiental e o potencial do contexto escolar diante dessa problemática.

Produção textual sobre Educação Ambiental das Infâncias: escreve um texto (máximo

Módulo 3 - Educação Ambiental das Infâncias nas Escolas e nas Famílias (27 de agosto a 03 de setembro de 2018)
1 lauda), apresentando uma discussão sobre a Educação Ambiental na Escola e na Família. Tente responder, no decorrer: 1) Qual a importância dos contextos ecológicos Escola e Família para a Educação Ambiental da infância? 2) Quais as possibilidades e os desafios de realizar a Educação Ambiental no contexto escolar e familiar?
Módulo 4 - Educação Ambiental das Infâncias e outros contextos ecológicos (03 a 10 de setembro de 2018)
Para finalizar o Curso, solicitamos a apresentação de um breve relato (no máximo 3 laudas) sobre o desenvolvimento da ação proposta no módulo 1, além do preenchimento da avaliação do Curso e as sugestões para qualificar ainda mais esta proposta.

Módulo 5 - Avaliação do Curso, Termo de Assentimento e Termo de Consentimento Livre e Esclarecido.

Questionário avaliativo do Curso (perfil dos educadores).

FONTE: Dados da pesquisa

Nas duas primeiras semanas do Curso, os fóruns foram mediados pelas pesquisadoras. Além dessas responsáveis, contamos com uma tutora4 para as interações com os educadores das infâncias. De acordo com Martins e Alves (2016, p. 111) "o fórum de discussão é uma ferramenta que permite prevalência dos aspectos qualitativos pelo caráter subjetivo imbuído em sua proposta”. É interessante mencionar que a conversa nos fóruns é um importante momento para investigar as percepções das educadoras das infâncias sobre as práticas educativas realizadas em diferentes contextos microssistêmicos.

No decorrer, segue a explicação da proposta do Plano de Ação e o posterior desenvolvimento da microintervenção, em que os educadores escolheram realizar com as crianças e/ou na formação docente. 0 modelo de intervenção sistêmico emergiu a partir do levantamento das informações pelos relatos e demandas resultantes da análise das informações obtidas nos encontros presenciais. Com o intuito de traçar o perfil e conhecer as perspectivas dos educadores sobre a Educação Ambiental das Infâncias, organizamos um questionário semiestruturado, consistindo também na avaliação do Curso.

Os procedimentos éticos foram essenciais ao estudo. Os educadores das infâncias tiveram que preencher o Termo de Consentimento Livre e Esclarecido- TCLE e as crianças, os Termos de Assentimento (TA), ambos elaborados de acordo com as orientações do Comitê de Ética em Pesquisa com Seres Humanos da FURG- CEP/FURG (Resolução 013/2019) da Universidade Federal de Rio Grande- FURG, através da Plataforma Brasil (BRASIL, 2019). Foi aplicado o TCLE para assinatura e concordância de todos os educadores das infâncias participantes do Estudo. Além disso, os responsáveis legais pelas crianças assinaram o TCLE aos educadores nos contextos ecológicos microssistêmicos. Os desenhos construídos pelas crianças corresponderam ao Termo de Assentimento (TA) (MISSIO e ARPINI, 2018).

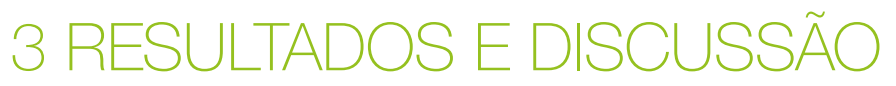

As ações que ocorrem dentro dos contextos ecológicos microssistêmicos são relações face a face e são aqueles ambientes mais próximos, como as escolas, as famílias, as instituições de acolhimento, dentre outros contextos (BRONFENBRENNER, 2011; PISKE; YUNES; GARCIA, 2019). É importante ampliar o debate sobre essa ideia, inserindo as mídias na Educação, o uso da Plataforma Moodle para a formação docente; embora, de certa forma, as pessoas não estejam no mesmo local, ficam estabelecidas relações proximais.

4 Márcia Soares da Silva. Pedagoga. Doutoranda pelo Programa de Pós-Graduação em Educação Ambiental (PPGEA/FURG). Professora da Rede Municipal de Rio Grande. Colaboradora do Grupo de Estudos Ecoinfâncias. 
Neste ínterim, importantes questionamentos surgem: o que são essas relações face a face? Através da Plataforma Moodle, ocorrem relações proximais? A face a face é estar frente a frente com uma pessoa? É possível estabelecer uma relação face a face ao utilizar os computadores? A interação por meio da Internet também é um microssistema? Será que ocorrem processos proximais neste contexto virtual? As relações que estabelecemos com os meios tecnológicos, com os objetos eletrônicos podem ser considerados como processos proximais?

Bronfenbrenner (2011), em sua teoria não se dedicou às relações com as tecnologias devido ao período histórico, mas em nenhum momento de suas produções mencionou que é indispensável à presença física, o que importa é a relação nos contextos microssistêmicos e as experiências que são compartilhadas. A Plataforma Moodle é um contexto fluídico, não é o lugar que estamos fisicamente. Todavia, no Curso de Extensão a distância tivemos a oportunidade de refletir sobre as relações face a face, pois nesta Plataforma os conhecimentos são compartilhados, cada pessoa no seu contexto microssistêmico, mas de fato fortalecendo os saberes reflexivos, que são práticos e sensibilizados pela conversa registrada nos fóruns. Sendo assim, a partir do momento que temos em comum as experiências que estão dentro dos mesmos contextos ecológicos microssistêmicos, esses experimentos são formativos, são espaços de encontro das pessoas via Plataforma Moodle, as perspectivas são compartilhadas e a influência mútua acontece.

A continuidade das interações na Plataforma Moodle é fator essencial para as reflexões nos contextos ecológicos microssistêmicos, em que as relações que são estabelecidas com as tecnologias podem ser consideradas como processos proximais. Esses processos exigem exatamente essa continuidade, a frequência. 0 processo gradual é cada vez mais complexo exatamente, o que Bronfenbrenner (2011) defende como processos proximais. Evidentemente, existem atividades que são interativas, mas as mesmas não geram processos proximais, pois não tem continuação. Esse é um fator significativo para pensar os processos proximais, pois para existir relações face a face é necessário ter continuação, uma complexidade cada vez maior, é cogente ter um vínculo causado. Essa continuidade pode ser gerada a partir de uma rede social, da Plataforma Moodle, mas é preciso ser contínuo, gradual e gerar vínculo. Desse modo, se for um encontro pontual, apenas um episódio isolado não se considera processos proximais. Os processos proximais demandam continuidade, sendo assim as interações face a face na Plataforma Moodle independem da presença física, as relações são estabelecidas pelas experiências compartilhadas por um longo período.

Em relação à presencialidade, atualmente existem muitas discussões acerca do termo virtual (HECKLER; MOTTA; GALIAZZI, 2016), o sujeito está presente apenas não fisicamente, mas geograficamente sim. De acordo com Tori (2017) é a educação sem distância, a transformação do significado das tecnologias digitais para a formação docente. 0 uso das tecnologias como um ambiente de interação é uma questão a ser (re)pensada com os educadores ambientais das infâncias. Por isso, o uso da Plataforma Moodle como mecanismo de interação e relação sistêmica na construção de Cursos de Extensão semipresencial.

Os sistemas são complexos e compostos por elementos indissociáveis; destacamos a Plataforma Moodle e os encontros presenciais. As microintervenções psicocorporais sensibilizadas nos encontros presenciais foram a possibilidade de reflexão, de acordo com Piske, Garcia e Yunes (2021, p.12): eu-pessoa, quem sou eu? Quem somos nós? Quais são as práticas educativas realizadas? A dinâmica de interação pela conversa(ação) sistêmica foi experienciada a partir das vivências psicocorporais construídas com os educadores nos encontros presenciais. Conforme podemos visualizar a seguir:

Figura 1 - microintervenções psicocorporais no desenvolvimento humano nas/das (com/para as) infâncias nos Polos

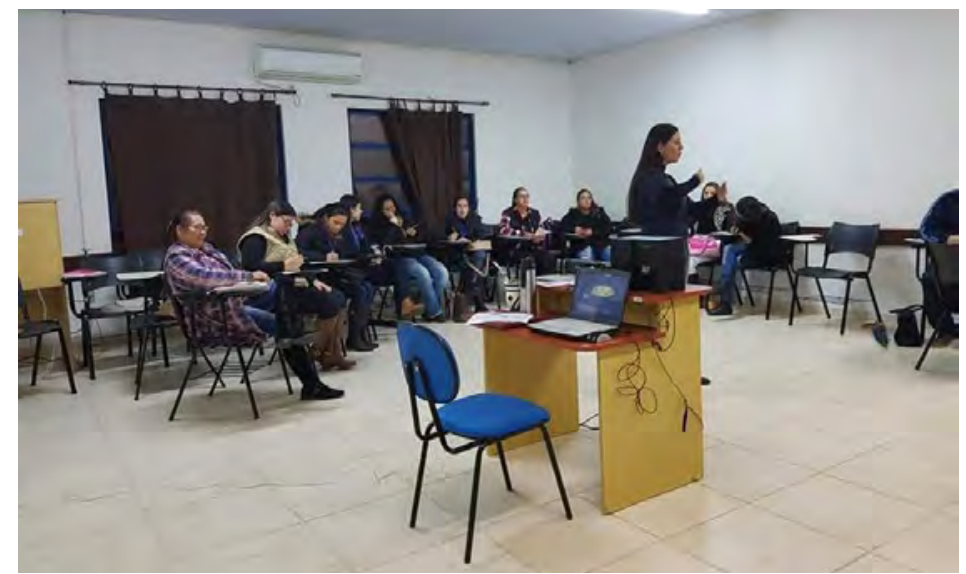

FONTE: Dados da pesquisa, 2018 
Os encontros presenciais foram uma busca e reflexão do eu-pessoa, quem sou eu? Quem somos nós? As informações apresentam que não podemos e não devemos nos restringir apenas em um determinado contexto microssistêmico, de acordo com Carvalho, Pedrosa e Rossetti-Ferreira, (2012, p. 51): "falar em cultura implica necessariamente falar em vida social". O que corrobora com o argumento de que as tecnologias são importantes contextos ecológicos microssistêmicos.

Não existe um mundo pré-anunciado igual para todos: o Planeta que está aí é o ambiente em que nós vivemos e as relações face a face são estabelecidas, escolhidas e firmadas nos múltiplos contextos ecológicos microssistêmicos, locais que transitamos. Em harmonia com o olhar bioecológico, em que não pode contemplar os elementos sob uma única perspectiva, todas as conexões produzem fenômenos que são conectados. 0 olhar bioecológico compreende essa complexidade que precisa ser vista na totalidade de atuações.

A relação entre sistemas não é uma analogia direta, o desenvolvimento humano não é linear e ascendente, passa por uma série de coisas que são maiores do que a compreensão do mundo. Mas, ao ter o olhar bioecológico todas as conexões são possíveis, as bases das relações estão na idéia de que sempre é contemplada para a pessoa e os demais elementos que são produzidos, isso é conexão sistêmica: o olhar bioecológico.

Para que as interações humanas ocorram no sistema, são cogentes quatro níveis de percepções: pessoa, processo, contexto e tempo-PPCT (BRONFENBRENNER, 2011)sem sobrepor a nossa Casa Comum, a Terra. A expressão "Casa Comum” foi cunhada por Boff (2012). A Casa Comum envolve o entendimento e a concepção dos fenômenos em uma perspectiva sistêmica bioecológica.

Para a construção de uma conversa(ação) sistêmica com os educadores ambientais das infâncias na formação docente foi necessário potencializar a "auto(trans)forma(ação)" educadora ao conectar as dimensões bioecológicas: PPCT (BRONFENBRENNER, 2011; PISKE; GARCIA, 2019). Os caminhos da educa(ação) se fazem trilhando o presente, o agora! Por isso, as trajetórias educativas são (fazem) a diferença ao conviver. A junção das estratégias pelas dimensões da biologia-cultural e da Bioecologia do Desenvolvimento Humano foram uma possibilidade para desenhar o Curso de Extensão Educação Ambiental das Infâncias, em que participaram educadores ambientais das infâncias de três cidades no Rio Grande do Sul: Rio Grande, São Lourenço do Sul e Santo Antonio da Patrulha. Em cada um dos Polos foi realizada uma microintervenção presencial a partir de práticas psicocorporais sensibilizadas com os educadores ambientais das infâncias. Em seguida, as orientações das atividades a distância do CEEAl foram disponibilizadas. As atividades a distância foram realizadas no Ambiente Virtual de Aprendizagem- AVA/FURG, desenvolvido na Plataforma Moodle, de acesso aberto pela Secretaria de Educação a Distância- SEaD/FURG.

O CEEAl começou com 80 cursistas, sendo 68 mulheres e 12 homens. Destes, concluíram o Curso 46 educadores das infâncias: 38 mulheres e 8 homens. Os fóruns foram espaços que os educadores ambientais das infâncias tiveram para conversar acerca das temáticas propostas. No fórum 1, foram mobilizadas discussões sobre as infâncias e a atuação educadora ao perpassar os elementos: culturas, ambientes e ludicidade, que são inerentes com as infâncias contemporâneas. Recordamos de uma situação narrada no encontro presencial ao (re)lembrar:

Certa ocasião, durante uma conversa, uma colega professora contou-me que dias atrás estava almoçando em sua casa e o telefone não parava de tocar. Eram colegas suas querendo acertar algum detalhe de trabalho, uma reunião etc. Depois de vários atendimentos ao telefone, quando este tocou novamente, a colega pediu para que sua filha, uma menina de cinco anos de idade, atendesse. A menina atendeu e falou para ela: "mãe é sua colega de trabalho". A mãe responde: "filha diz pra ela que não estou". A menina, surpresa, pergunta para a mãe: "Mas mãe, tu estás pedindo para eu mentir para tua colega"? Vocês não são amigas? "Tu não me diz, sempre, que mentir é feio?" Se refletirmos a partir do que vimos até aqui, penso que esta pequena narrativa de um fato cotidiano dispensa comentários (BARCELOS; MADERS, 2018, p. 65-66).

Com esta pequena situação podemos refletir, vivenciar e (re)pensar a atuação educadora. Será uma narrativa de um fato cotidiano? No fórum participaram da conversa 41 educadores ambientais das infâncias, conforme relatório de participação. Sendo que, apenas 9 deles fizeram colocações das crianças no presente.

Para a análise dos dados foi utilizado o minerador de textos, que se chama Sobek (EPSTEIN, 2017; COUTO, 2015): software que tem a funcionalidade de analisar as informações em forma de um grafo. O Sobek é um aplicativo desenvolvido pelo Programa de Pós-Graduação em Informática na Educação, na Universidade Federal do Rio Grande do Sul (UFRGS). As informações coletadas dos participantes ao procurar e inserir no software, os feedbacks, os textos eram tratados e gerava corpus. Sendo assim, o Sobek origina diferentes graphos, essas imagens podem servir em diferentes análises, o corpus apresentado por palavras, momento que vai aparecendo expressões, de acordo com as incidências ao longo do texto. Conforme se visualiza no 
grapho, aparece a presença da palavra "aqui", dentre outras demonstrações que surgem de acordo com a mineração de texto elencadas com a ferramenta Sobek:

\section{Figura 2 - Grapho Educação Ambiental das Infâncias- gerado no SOBEK}

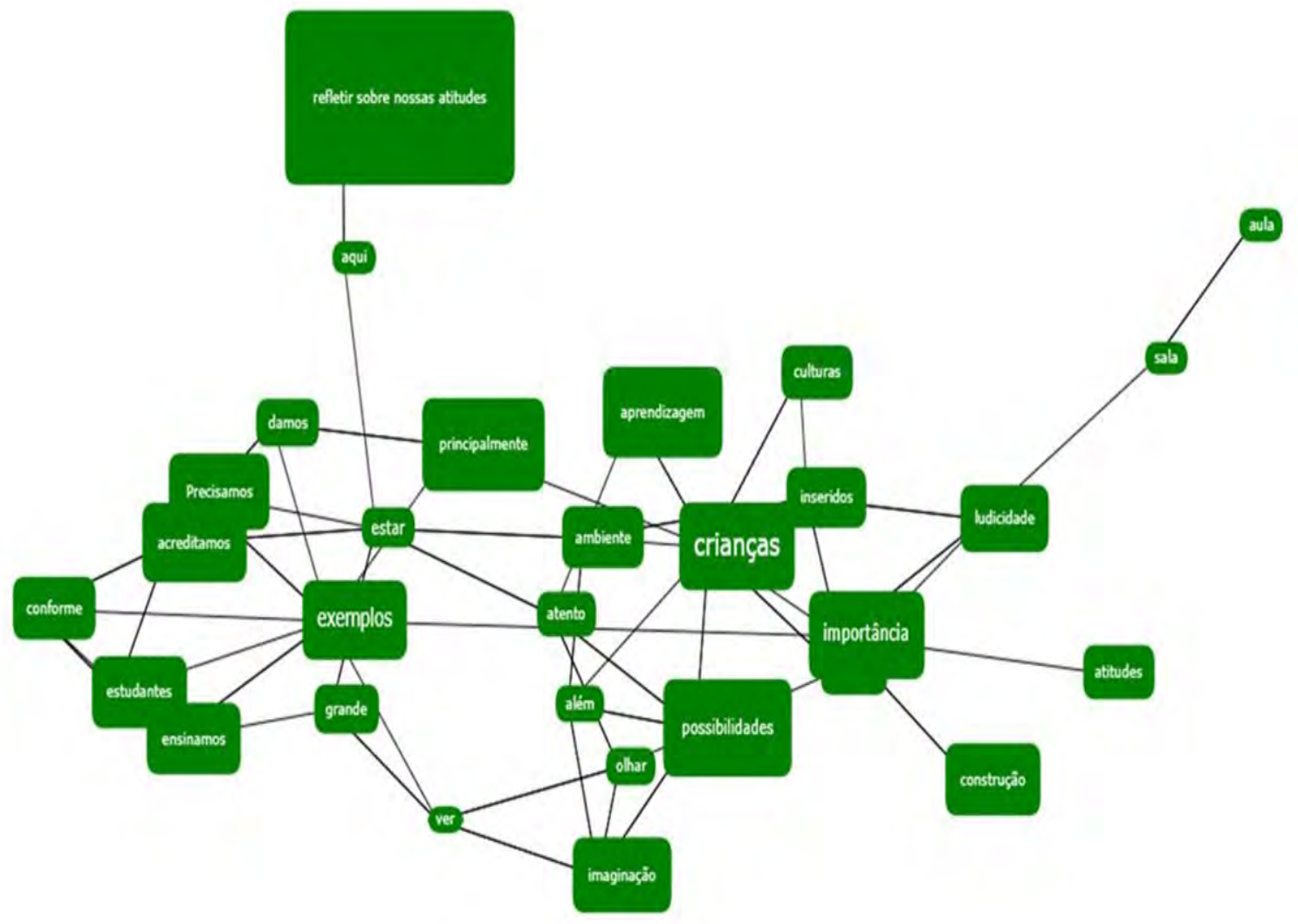

FONTE: Dados da pesquisa.

As palavras em destaque reforçam os papéis que os educadores das infâncias assumem ao enfatizar que as crianças vivem e são o hoje. São competências éticas do desenvolvimento humano diante do contexto atual, no presente, não do passado nem no futuro, por isso foi necessário pensar no aspecto tecnológico, na globalização, nas culturas, no consumo, nas questões de gênero, etnias e nas múltiplas linguagens e em todos os elementos que envolvem a sociedade hoje.

Os papéis dos educadores como acolhedores na aceitação mútua e no respeito contribuíram para alicerçar a conversa(ação) na Educação Ambiental das Infâncias nos múltiplos ambientes microssistêmicos. Foi a contribuição das concepções bioecológicas para a Educação Ambiental a partir do Projeto com os resultados entrelaçados. Ainda é recente falar das vicissitudes sistêmicas das infâncias que são mobilizadas com os educadores por meio do olhar bioecológico, talvez esse ainda seja um dos impasses para se perceber as teias que envolvem o tempo, o processo e suas múltiplas relações para uma educação nas/das (com/para as) infâncias.

O espaço compartilhado no fórum sensibilizou mostrando que o futuro da educação nas/das (com/para as) infâncias é o presente, o agora! Os educadores das infâncias precisam ser responsáveis por suas ações e corresponsáveis pela educação das crianças, pela autonomia e por possibilitar a construção reflexiva e a ressignificação pela interação nos ambientes.

Além deste Fórum, tivemos outros dois: um sobre a in/exclusão como parte da crise ambiental e o potencial do contexto escolar diante dessa problemática e o outro fórum um espaço para compartilhar os relatos acerca do Plano de Ação. Em suma, nos últimos fóruns, as expressões apresentam que não existe contexto ecológico sem ambiente, a questão ecológica tem relação com o lugar simbólico. Os caminhos da educa(ação) das infâncias se fazem trilhando o presente, o agora! Por isso, as trajetórias educativas são e fazem a diferença ao conviver com as diversidades. A rede que se forma é um permanente movimento que, embora os papéis sejam somados, nunca deixa de ser coletivo, pelo simples fato de constatar mais uma vez o que se aprendeu com Bronfenbrenner (1996), quanto mais papéis para o desenvolvimento humano, melhor é! 
0 momento da construção do Plano de Ação foi bastante delicado e desafiador, embora com a explicação proposta no encontro presencial a partir da construção de um Projeto de Educação Ambiental das Infâncias, os anseios e as incertezas relatados nos fóruns e através de emails enviados, demonstrava desconforto e inquietações dos educadores ambientais das infâncias para a criação do plano. As dúvidas em relação à construção da intervenção e ao desenvolvimento da proposta eram várias, assim como quanto à organização da ação.

É importante enfatizar que os fóruns de discussões foram um importante instrumento para a coleta de informações, local em que surgem as temáticas, tais como: jogos pedagógicos planisférico a partir de uma história: zoom; relações socioambientais nas feiras livres; coloque a mão na terra e sinta a natureza; conceitos multiculturais; perspectivas acerca do bairro; terrário; o ambiente pode ser transformado a partir do nosso olhar; as coisas que vimos ao nosso redor; associação de bairro; conhecendo sua história; a sala verde como espaço de Educação Ambiental das Infâncias; imaginário e a interatividade; reciclagem divertida; vivências com as infâncias no meio rural e o Jogo Minecraft; sustentabilidade ambiental; jogos teatrais; relações sociais; filme Wall-e; fabricar móveis com garrafas pet; sensibilizando todos; recontar histórias; para que serve a árvore?; sugere-se que a percepção pode ser trabalhada desde a infância; jardim suspenso; como cuidamos do lugar que vivemos?; coletor de óleo; aterro sanitário; plantar; água do nosso planeta; preservação ambiental; água como elemento interdisciplinar do ensino nas escolas; bilboquê; gincana da Glorinha; relacionamento das cores com os objetos de seu repertório; o processo cognitivo na Educação Ambiental; história na recicladora: alfabetização de jovens e adultos; Educação Ambiental e Infância; e reciclando e aprendendo sobre o sistema solar.

As diversidades temáticas apresentadas nos planos de ação estabelecem interlocução das concepções bioecológicas de desenvolvimento humano nas/das (com/para as) infâncias, temas que incidem os processos proximais e indicam para a construção de práticas psico(corporais)ambientais que envolvem a abordagem da Biologia-Cultural e das dimensões da Bioecologia do Desenvolvimento Humano na educação das crianças. Os processos proximais se referem às relações com o(s) outro(s), com os objetos, com os significados, com as linguagens e com os símbolos presentes nos contextos, sendo a oportunidade de refletir sobre a contribuição das tecnologias nos planos de ação.

Todas as dimensões têm repercussão nas concepções bioecológicas de desenvolvimento humano nas/das (com/para as) infâncias e são interativas, conforme se pode acompanhar com a ilustração acima. Sendo assim, a interação não ocorre somente com o outro humano, mas também com o outro não humano, alguns exemplos: o cachorro, a natureza e os demais elementos. Bronfenbrenner (2011) quando conceitua desenvolvimento humano menciona que o importante não é a realidade objetiva, mas o fato percebido pela pessoa que está em interação.

É necessário mencionar a implicação das redes sociais nas concepções bioecológicas de desenvolvimento humano nas/das (com/para as) infâncias. Mesmo virtualmente temos que trabalhar uma educação sem distância, então a aproximação que esses meios tecnológicos podem promover é outra forma de enxergar as questões; conforme Tori (2017), é uma educação mais interativa que se faz com o uso das tecnologias, sendo assim não falamos que estamos longe, mas geograficamente distantes. Pois, estamos próximos, mesmo geograficamente afastados.

Conforme já mencionado, Bronfenbrenner (2011) não dissertou que a Plataforma Moodle pode ser um dos contextos ecológicos microssistêmicos devido à conjuntura da época, mas atualmente as tecnologias digitais se inserem ativamente nos processos proximais, já que são relações que se consolidam, são atividades contínuas, que se tornam progressivamente mais complexas. Os dados que emergiram da análise em vários momentos, surpreendem ao trazer a conversa das crianças em decorrência das redes sociais, pois o conceito de "vozes das crianças" é complexo, ainda mais numa conversa(ação) com os educadores ambientais das infâncias na construção dos Planos de Ação. Por isso, o ponto de partida foi o campo, a prática, a observação, o acompanhamento, a ação, a reflexão e a teorização pela implicação dos educadores das infâncias aliadas ao protagonismo das crianças nos múltiplos contextos ecológicos microssistêmicos.

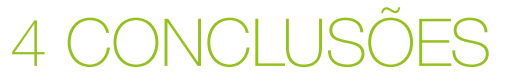

Com o estudo foi possível entender que tudo está relacionado com o tempo, o processo e o contexto, em que não é possível compreender a pessoa de forma dissociada do ambiente. Os processos educativos nos contextos consideram as experiências das pessoas e o tempo, sendo impossível separar os elementos, o que contribuiu sobremaneira para o constructo: Educação Ambiental das Infâncias. As preposições nas/das (para/com as) infâncias estiveram presentes na investigação, sendo intenção trazer ao destacar a força dos processos proximais na educação das crianças.

A perspectiva sistêmica e o olhar bioecológico constituíram os alicerces necessários para mobilizar novas estratégias para a formação docente em contextos ecológicos microssistêmicos. Em todos os 
comportamentos humanos é fundamental integrar os aspectos psico(corporais)ambientais, através de uma busca e reflexão do eu-ambiente, considerando que as interações face a face e os processos proximais foram construídos e fortalecidos pela Plataforma Moodle. Sendo assim, as práticas psico(corporais)ambientais e os registros nos fóruns mobiliza o olhar bioecológico sistêmico na Educação Ambiental das Infâncias, comprovase a necessidade da potência da ação com a conversa pela integralidade dos elementos na defesa de novas estratégias para a formação docente e discente.

A potência estrutural pela integralidade das dimensões complexas na investigação foi à possibilidade para apresentar o repertório teórico-metodológico direcionado para o Curso de Extensão Educação Ambiental das Infâncias, em que as ações mobilizaram novas estratégias para a formação docente, através da conversa(ação) com os educadores ambientais das infâncias. Vale mencionar o curso de extensão construído com os educadores ambientais das infâncias foi como um espiral, em que o movimento sinérgico com a Pesquisa, o Ensino e a Extensão foi a mola propulsora de desenvolvimento humano na educa(ação) das crianças nos múltiplos contextos ecológicos microssistêmicos.

\section{Agradecimento}

O presente trabalho foi realizado com apoio da Coordenação de Aperfeiçoamento de Pessoal de Nível Superior - Brasil (CAPES) - Código de Financiamento 001.

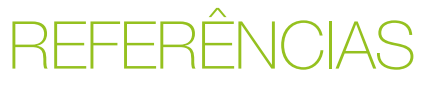

BARCELOS, Valdo; MADERS, Sandra. Humberto Maturana e a Educação: educar no amor e na liberdade. Santa Maria: editora e gráfica Caxias, 2. ed., 2018.

BERSCH, Angela Adriane Schmidt, PISKE, Eliane Lima; YUNES, Maria Angela Mattar; GARCIA, Narjara Mendes; SILVEIRA, Simone Batista A. Biazzi; PIETRO, Ângela Torma. Programa de Formação de Educadores Sociais na Promoção da Resiliência Profissional. In: Ângela Adriane Schmidt Bersch... [et al.]. - Rio Grande: Ed. da FURG, 2019. Disponível em: http://repositorio.furg.br/bitstream/handle/1/7867/EbookCompleto.pdf?sequence=3. Acesso em: 20 ago. 2019.

BRASIL. Ministério da Saúde. Orientações do Comitê de Ética em Pesquisa com Seres Humanos- CEP-FURG. Resolução 013/2019. Disponível em:https://propesp.furg.br/images/CEP-CHS/Instruo Normativa_06-2019CEP FURG.pdf. Acesso: 08 out. 2020.

BROFENBRENNER, Urie. A Ecologia do Desenvolvimento Humano. Experimentos naturais e planejados. 2. ed.. Porto Alegre: Artes Médicas, 1996.

BRONFENBRENNER, Urie. Bioecologia do desenvolvimento Humano: tornando os seres humanos mais humanos. Porto Alegre: Artmed, 2011.

BOFF, Leonardo. As quatro ecologias: ambiental, política e social, mental e integral. Rio de janeiro: Mar de ideias: Animus Anima, 2012.

COUTO, Zélia de Fátima Seibt. Metadesign educacional: a autonomia compartilhada como cultura emergente da convivência digital. Tese de doutorado, Programa de Pós-Graduação em Educação Ambiental, FURG, 2015. Disponível em: https://argo.furg.br/?BDTD10732. Acesso em: 23 ago. 2020.

CARVALHO, Ana; PEDROSA, Maria Isabel; ROSSETTI-FERREIRA, Maria Clotilde. Aprendendo com a criança de zero a seis anos. São Paulo: Cortez Editora, 2012.

EPSTEIN. Daniel. Uso do minerador de textos Sobek como ferramenta de apoio à compreensão textual. Tese de Doutorado, Programa de Pós-Graduação em Informática na Educação, Universidade Federal do Rio Grande do Sul. Rio Grande do Sul, Porto Alegre, 2017. Disponível em: https://www.lume.ufrgs.br/bitstream/ handle/10183/178332/001066224.pdf? sequence=1\&isAllowed=y. Acesso em: 27 ago. 2018.

HECKLER, Valmir; MOTTA, Cezar Soares; GALIAZZI, Maria do Carmo. A experimentação em ciências constituída na interatividade online. Revista de educação a distância - Em Rede, v. 2, p. 129-143, 2016. Disponível:https:// www.aunirede.org.br/revista/index.php/emrede/article/view/61. Acesso em: 09 nov. 2018. 
MARTINS, Alexandra da Costa Souza; ALVES, Lucicleide Araújo de Souza. O Fórum de Discussão como Instrumento Avaliativo de Aprendizagem. Informática na Educação: teoria \& prática, Porto Alegre, v. 19, n. 2, p. 106-122, jun./set. 2016. DOI: https://doi.org/10.22456/1982-1654.62540. Acesso em: 14 nov. 2020.

MATURANA, Romesín Humberto; DÁVILA, Yáñez, Ximena. Habitar humano em seis ensaios de biologia cultural. Tradução de Edson Araújo Cabral. São Paulo: Palas Athena, 2009.

MINAYO, Maria Cecília de Souza. Pesquisa social: teoria, método e criatividade. Petrópolis: Vozes, 2010.

MISSIO, Joana; ARPINI, Dorían Mônica. El juego en la vivencia de calle de los niños: retratos y narraciones a partir de Dibujos-Historias. Sociedad e Infancias, 2018. Doi: SN: 2531-0720 http://dx.doi.org/10.5209/SOCl.59347. Acesso em: 26 out. 2018.

PISKE, Eliane Lima; YUNES, Maria Angela Mattar; GARCIA, Narjara Mendes. Ambientes educativos como contextos microssistêmicos para o desenvolvimento humano na infância. Educação e Saúde- Dossiê do Meio Ambiente. Revista Eletrônica Itinerarius Reflexionis. v. 15, n. 1, 2019. ISSN 1807-9342, 2019. Disponível em: https://www.revistas.ufg.br/rir/article/view/58821. Acesso em: 06 dez. 2019.

PISKE, Eliane Lima; GARCIA, Narjara Mendes; YUNES, Maria Angela. Práticas educativas ambientais na formação de educadores das infâncias. Texto Livre Linguagem e Tecnologia. Belo Horizonte, v. 14, n 1, jan.- abr., 2021. Disponível em: https://periodicos.ufmg.br/index.php/textolivre/article/view/25698. Acesso em: 13 mar. 2021.

PISKE, Eliane Lima; BERSCH, Angela A. S.; PIETRO, Angela T.; VIEIRA, Gabriela; YUNES, Maria Angela Mattar; GARCIA, Narjara Mendes; SILVEIRA, Simone A. B. Educa(ação) humanizadora: Programa Centro de Referência em Apoio às Famílias. In: Extensão universitária da FURG [recurso eletrônico]: a produção de conhecimentos a partir da prática extensionista / Daniel Porciuncula Prado, Carla Amorim Neves Gonçalves, Beatriz Spotorno Domingues, Organizadores. - Dados eletrônicos. - Rio Grande, RS: Ed. da FURG, 2020. Disponível em: http:/l repositorio.furg.br/handle/1/9308. Acesso em: 16 mar. 2021.

PISKE, Eliane Lima; NEUWALD, Mariana Costa; GARCIA, Narjara Mendes. Sustentabilidade ambiental, a ética nas e com as relações humanas e as interações afetivas: tríade necessária às pesquisas em Educação Ambiental.

Rev. Eletrônica Mestr. Educ. Ambient. Rio Grande, Ed. Especial EDEA, n. 1, p. 88-101, 2018. E-ISSN 15171256. DOI: https://doi.org/10.14295/remea.v0i1.8565. Acesso em: 25 jul. 2020.

PISKE, Eliane Lima; GARCIA, Narjara Mendes. Conversa(ação) sistêmica para potencializar a (trans)formação de educadores ambientais das infâncias. In: 39 Reunião Nacional da ANPEd- Educação Pública e Pesquisa: ataques, lutas e resistências. Anais 39 Reunião Nacional da ANPEd Rio de Janeiro, 2019. Disponível em: http://39.reuniao.anped.org.br/category/trabalho/?grupo trabalho=gt22-educacao-ambiental. Acesso em: 16 mar. 2021.

TORI, Romero. Educação sem distância: as tecnologias interativas na redução de distâncias em ensino e aprendizagem. São Paulo: Artesanato Educacional, 2017. 